\title{
Assessment Experiences of Students with Disabilities in Higher Education: A Case of Students with Disabilities at one Higher Education Institution in Masvingo District of Zimbabwe
}

\author{
Podzo Barbara Zvisinei Chipika Charles Govero \\ Faculty of Education, Reformed Church University, Zimbabwe
}

\begin{abstract}
Assessment forms an integral part of the learning process in higher education where knowledge is tested and applied in various ways. While various methods are employed by assessors ranging from formative to summative assessments, a high degree of integrity is required from those tasked with assessing the students. Ethics, honesty and integrity are the forgotten pillars of assessment which often do not reflect in the assessment task but in the individuals tasked with ensuring academic quality. This qualitative study must be understood as an attempt to close the gap in the literature and to provide a deeper understanding of:

- the assessment challenges faced by students with disabilities in Higher Education (HE);

- accommodations which are being offered and other measures which are in place to enhance inclusive assessment; and

- $\quad$ suggested strategies to promote inclusive assessment of students with disabilities (SwDs) in HE.

Data collection involved individual interviews and focus group discussion with students with various impairments on their assessment experiences. Findings reveal that generally SwDs still face assessment challenges although there are marked improvements on their accommodations. Lack of access to information in accessible formats, lack of computer and Braille skills were also cited as challenges SwDs were facing. Participants expressed satisfaction on how examinations were administered as they could write using the modes they were comfortable with. These modes included audio, Brailling and use of computers. Students applauded the University as it allowed them extra time for writing their examinations. Participants also expressed attitudinal as well as financial challenges during their work related learning/teaching practice in addition to lack of Braille and computer skills by both learners and staff..

The study concludes that SwDs still experience assessment challenges although to some extent HEIs have put in place some practices to the benefit of SwDs. In light of the foregoing findings and conclusions, the researchers therefore recommend the following:

- The University should invest in assistive technologies including embossers, scanners and the relevant software like JAWS for the benefit of students with disabilities

- The university should equip staff with such basic skills like Brailling and training in basic disability issues through regular disability awareness campaigns

- The Institution should incentivise helpers of students with disabilities in the form of, for example free accommodation

- The University should establish a Disability Resource Unit and engage a fulltime Disability Resource Unit Officer

- The university should sensitize staff and students about the Disability Policy and walk the talk in its implementation.

- The government should complement by paying some allowances to University SwDs on Work Related Learning/Teaching Practice to enable them meet extra costs associated with their impairments
\end{abstract}

Keywords: Assessment, Alternative assessment, Inclusive assessment, Summative assessment, Formative assessment, Students with disabilities.

DOI: $10.7176 / \mathrm{JEP} / 10-18-06$

Publication date:June $30^{\text {th }} 2019$

\section{Introduction}

Assessment is a critical component of the curriculum of any educational institution. Tennant, McMullen and Kaczynski (2010:93) argue that "assessment is a significant lever for change and improvement in students' learning experiences in higher education". Assessment can either be formative (continuous) or summative to determine students' knowledge, skills, attitudes and contribute to their final grade. It can either be informal through observations and or oral questions, or formal through final examinations (Gebrehiwot, 2015). For this to happen, assessment should follow certain principles, one of which is fairness. This ensures that no student is disadvantaged or advantaged (Shepherd, 2006). Chataika (2007) emphasised the significance of flexibility in the mode of measurement so that the principle of fairness is realized in assessment.

Different surveys indicate that the number of students with impairments who are enrolled in higher 
education (HE) is on the rise (Gebrehiwot, 2015) and yet teaching, learning and assessment remain areas of particular concern to their inclusion (Tinklin, Riddell and Wilson, 2004). Tennant et al. (2010:93) indicate a new situation calling for a change in the assessment practices of HE as observeded below:

- The increased student population in HEIs has increased pressure for cost effective assessment.

- The increasing diversity of the student population has forced universities to reassess accepted ideas about what can be expected from students and has forced them to provide greater support for students from diverse backgrounds to achieve assessment standards.

- Demand from stakeholders that education be relevant to working life and for universities to produce 'work-ready' graduates has contributed to a focus on assessment of generic skills as well as disciplinary content and greater attention to 'authentic assessment'.

- Increased concern with accountability and quality assurance has seen greater institutional interest and intervention in assessment practice and standards.

- The transforming effect of information and communication technologies presents new possibilities for assessment.

In general, assessment creates anxiety for all students, but research has revealed that the modes of assessment used in HEIs are most restrictive for SwDs (Vickerman and Blundell, 2010). The same authors further express that there is lack of improvement in making assessment practices accessible to SwDs. If students with impairments in higher education institutions are to enjoy equal opportunities and participate fully in the teaching, learning and assessment process as their non-disabled counterparts, issues of access and equity need to be addressed (Podzo \& Chipika, 2019). The disparity in educational access and attainment between learners with and without disabilities implies that there are challenges which militate more against learners with disabilities than their non-disabled counterparts. Although Shakespeare (2006) concurs with this, he further points out that as far as learning needs are concerned, it is invidious to treat learners with disabilities as a separate category, rather they fall along a continuum of learner differences and share similar challenges and difficulties with varying degrees of severity. This inequality and marginalization of learners do not pertain to academic issues alone, but it is also experienced when it comes to provision of extra-curricular activities and participation thereof by learners with disabilities. Brunton and Gibson (2009) are of the view that challenges and needs of learners with disabilities must be perceived as a multi-dimensional issue that places a heavy demand on both the learner to cope and the HEI to make 'reasonable adjustments' in the learning environment in order to accommodate all categories. Makanya (2015) argues that alternative curricular materials, pedagogical and inclusive assessment practices are necessary to meet the needs of SwDs. Important among many other considerations, certain adaptations and modifications have to be made to the assessment of SwDs and thus calling for culture change. Howell (2006) states that learners with disabilities who have managed to attend higher education complain that the energy, emotional, resources and levels of stress involved in dealing with the overwhelming range of barriers that confront them are extremely undermining and place them at an ongoing disadvantage to other learners. Assessment remains focused on the learning achieved by an individual student, with little attention to the social context in which learning takes place.Tugli (2013:57) asserts that barriers to learning arise from within the various interlocking parts of the curriculum such as assessment methods and techniques. Thus, tertiary institutions should ensure the provision of universal services which include positive attitudes and inclusive educational systems to students with disabilities.

Lerner and Johns (2012) indicate that the inclusion of SwDs requires educators to adapt their teaching curriculum. This must however be done without sacrificing the integrity of the content. Thus, alternative means of assessment should not compromise standards. There is continuing argument that there is too much assessment in HE which encourages assessment-led students, rather than learning-led students. The standard forms of examination and written assignment have remained largely unchanged for many decades despite the on-going focus in development and research work on how to improve assessment technologies (Elton, 2004). Leathwood (2005) notes that some attempts to modernize assessment in HE such as new focus on student self-assessment and criterion-referenced assessment, which may have their roots in student empowerment narratives may in practice be experienced as new forms of regulation and surveillance by students and staff and may do little to change structural inequalities in assessment systems. Further to that there is confusion of terminology relating to the ways in which institutions internationally apply compensatory adjustments or provisions (for example extra time, amanuensis, separate room and others) to current assessment methods for students with disabilities. Variously these include 'special arrangements', 'reasonable adjustments', 'assessment provision' (United Kingdom- UK), 'accommodations' (United States of America-USA), and 'alternative assessments' (Australia) (Waterfield and West, 2006). The same authors express that this is confusing for transnational student mobility and for staff as far as assessment of learners with impairments is concerned. The current system for assessing disabled students reflects societal inequality where participation in education continues to be focused on fitting people into what is already available (Stuart, 2002). The majority of alternative assessments are still provided on a "one off" basis to meet individual need. When assessment focuses on categorical differences between learners 
such as 'disabled/ non-disabled', it misses the many differences between learners across categories (Rose \& Meyer, 2000). Waterfield and West (2006) propose three frameworks for considering current practice and planning for assessment as follows:

- Contingent approach "special arrangements" such as extra time, amanuensis, own room and others which is essentially a form assimilation into an existing system;

- Alternative approach e.g. viva voce instead of a written assignment, offering a repertoire of assessments embedded into course design as present and future possibilities for a minority of disabled students;

- Inclusive approach e.g. a flexible range of assessment modes made available to all, capable of assessing the same learning outcomes in different outcomes in different ways.

Sharp and Earle (2000) have argued that the idea of compensation for disabled students is highly questionable. Alternative assessment, they maintain, are only acceptable if they are genuinely equivalent in terms of the skills and knowledge they test, and if this is the case, then all students should be allowed access to adjustments, which might include extratime, the use of typical forms of assessment, such as three hour exams, should be examined much more critically, with a view to establishing whether the knowledge and skills required to succeed in such an activity are intrinsic to the requirements of the course which is being assessed. In some cases unfair practices like giving SwDs class average as their final examination mark, exempting SwDs from challenging tasks are offensive (Haihambo, 2010). Thus training instructors on how to handle SwDs becomes prudent.The special arrangements approach to assessment does not necessarily produce an enabling environment or student satisfaction due to: lack of resources such as assistive devices, equipment failure, inappropriate practical arrangements and a shortage of adequately trained readers, scribes and invigilators. There is a widespread sense in HEIs that 'special arrangements' represent host institutions making these arrangements to existing practices with challenges as they have grown exponentially, unplanned and based on a philosophy of accommodating disabled people. They set students with disabilities and those with no developmental delays apart from one another, creating spheres of suspicion and discourses of inequality and privilege (Waterfield \& Meyer, 2006). Fuller, Georgeson, Healey, Hurst, Riddell, Roberts and Weedon (2008) have argued that it is invidious to treat students with disabilities as a separate category as they fall along a continuum of learner differences and share challenges and difficulties with other HE students. These barriers are sometimes more severe for students with disabilities but sometimes they are not. The same authors further express that the main beneficiaries of disability legislation may be non-disabled students as many of the adjustments introduced to help disabled students such as:

- Well prepared handouts;

- Notes put online;

- Instructions given in writing as well as orally; and

- Variety and flexibility in forms of assessment are good teaching and learning practices which benefit all students.

Ashworth, Bloxham and Pearce (2010) question existing methods of assessment as biased against students with disabilities and using the deficit model that gives credit to some students for passing and blame those who cannot pass as incapable despite unjust and partial institutional practices. Assessment has traditionally brought rewards to some while condemning others (Mosia, 2017). Arguments for access state that assessment should improve from evaluating how much content can be recalled to assessment of quality of thought (Nkoane 2006:51). Students' differing scores should be perceived to reflect diversity of student population rather than inferiority (Ashworth et al. 2010:221), and not promote current power politics where the teacher is the 'know it all' and requires everyone to be the same and meet certain norms and standards (Nkoane 2006:50). For example assessment should consider how limited resources affect teaching students with visual impairment (Mokiwa \& Phasha 2012:145). Assessment from the social model should evaluate the quality of learning, and would therefore, go beyond the paper-pencil format to include oral examinations, practical display of acquired skills and production of novel ideas as a result of learning and would reflect diversity and flexibility.

In spite of many countries being signatories to United Nations (UN) convention on inclusive education, most literature show that most countries have not domesticated these, Zimbabwe included (Podzo and Chipika, 2019). International experiences tell us that for the effective provision of support to SwDs, countries should have legislation in place which could be adopted by institutions to guide their operations. Therefore, it is the responsibility of HEIs to develop policies or any specific guidelines that guide their support systems.

\section{What is assessment?}

Ioannou-Georgia (2003) defines assessment as a general term which includes all methods used to gather information about the learner's ability, understanding, attitude, knowledge and motivation. It is a process used by instructors to gather data about teaching and their students' learning. The data provide a picture of a range of activities using different forms of assessment such as exams, tests, assignments and others. Once these data are 
gathered, then evaluation of students' performance can be done which establishes strengths and weaknesses for future intervention. Assessment cannot be separated from evaluation as it influences the latter. The same author views evaluation as a process of gathering information inorder to determine the extent to which a programme meets its goals. Some of the tools of the evaluation process are test,questionnaires and or observations.Relevant information can be teachers and parents' opinions, examination results and the learners' attitudes.Evaluation refers to a broader notion than assessment (Cameron,2001). The cycle is incomplete without mentioning the term "feedback". The essence of assessment is to measure progress on an intervention and thus the information needs to be relayed to the intended destination. Cameron (2001:288)views feedback as information or response given to the learner, regarding his or her performance,so that it might be improved. Cameron 2001 states that, if assessment feedback is to be helpful to learners and improve their learning, it needs to be specific and detailed enough to make a difference and equally importantly, it needs to be related to a target performance or understand towards which the learner can learn more as a process. Assessment is used widely for all those activities that involve eliciting evidence of student learning and drawing inferences as basis for decision making.All assessments involve certain processes associated with making observations of performance, interpreting the evidence and making judgments that can inform decisions.

\section{Rationale for Educational Assessment}

Effective feedback on work submitted is crucial in helping students learn by pinpointing where they may be going wrong and what they need to do to improve. One of the most important drivers of student learning is how that learning is assessed and it has been shown that students' attitudes towards their studies are strongly affected by the nature and timing of assessment (Murphy, 2009). Assessment does not measure achievement of learning outcomes but it also classifies or grades student achievement. Well-timed and well-designed assessment can have a powerful impact on how students approach their learning. Importantly it also gives lecturers indications of how effective their teaching approaches that are in terms of student progress. The primary purpose of assessment is to improve students' learning and instructors' teaching as both respond to the information it provides. It can do more than simply diagnose and identifying students' learning needs; it can be used to assist improvements across the education system in a cycle of continuous improvement; students and teachers can use the information to determine their next teaching and learning steps; school leaders can use the information for school-wide planning to support their teachers and determine professional development needs; can be used for policy review and development at a national level, so that the government funding and policy intervention is targeted to improve student outcomes. Effective feedback on work submitted is crucial in helping students learn by pin pointing where they may be going wrong and what they need to do to improve.

\section{Functions of Assessment}

Kratochvilova(2011:24) defines four main and basic functions of assessment as follows:

- Corrective

- Motivational

- Developmental

- Informative

Besides the functions stated above, Kolar and Sikulova (2005) established several additional ones as follows:

- Prognostic

- Differential

- Formative

- Regulative

\section{Informative function of assessment}

It has its importance for the learner, instructor and parents. Information provided should be concrete and on time. Informative information allows the learner to see his/her achievement, progress and also lays a platform for them to compare their performance with their peers.

\section{Corrective function of assessment}

Kolar and Sikulova (2005:25) divided the corrective function of assessment further into regulative, prognostic and differential function (also called developmental, Kratochvilova (2011:25). The information enables the learner to search, either individually or with help for a way to improve his or her results and also the direction to take in order to improve the results (Kratochvilova, 2011: 24).

\section{Regulative Function of Assessment}

It appears every time when the instructor assesses the learners. The information facilitates procedure to correct 
errors and a process to avoid those errors in the future (Kolar and Sikulova, 2005:49).

\section{Development Function of Assessment}

It is equally important information as it has an effect on the overall development of the learner. It facilitates development of the learner's required skills, personality and his/her self-perception.

\section{Motivational function}

It provides motivation to the learner through the instructor's feedback. According to Kolar and Sikulova (2005), motivational function of assessment is the strongest and also the most frequently used (and misused) function. Engaging the learners in the creation of thecriteria according to which they will be assessed and in the assessment itself might increase the sense of responsibility in the learners and motivate them to learn.

\section{Types of Assessments}

Finding the right assessment method depends on what you are really trying to assess in terms of skills, knowledge or understanding. There are various types of assessments used for different purposes. All assessment techniques have limitations, either for students or marking staff and there is no single assessment technique that results in a perfect assessment. Finding the right assessment depends on what the assessor is really trying to assess in terms of skills or knowledge or understanding. In some circumstances the assessor's ignorance and resultant attitude influence them to overlook students' challenges in class and make no adjustments to their teaching and assessment methods, thus leaving students vulnerable and lacking access to the curriculum (Cameron and Nunkoosing 2012). In light of this, care must be taken that assessment is not onlycarried out using one criterion such as cost effectiveness. Assessment of students should be appropriate to the discipline and allow for diversity of the student profile. Consideration could also be given to assessing students on competence as well as content. All of the different assessment types work together to provide a complete, valid, reliable and fair picture of a student's performance. Above all, assessment should be:

- Valid, reliable and consistent;

- Diverse;

- Transparent;

- Fair;

- Useful to ensure student learning is enhanced

- Promoting deep learning (Race, 1998).

Assessment can be formal or informal and or diagnostic. Informal assessment involves:

- circulating the classroom and posing questions, guiding investigations, motivating and quizzing students,

- Providing opportunities for students to present or report upon their learning and teaching experiences;

- Collecting, analyzing and providing feedback on in and out of class work samples.

- Systematically observing and monitoring students during in class learning and teaching experiences;

- Interacting with students to gain deeper knowledge of what they know, understand or can do.

\section{Formal Assessment}

It involves use of specific assessment strategies to determine the degree to which students have achieved the learning outcomes. Formal assessment strategies include: examinations, essays, reports, projects, presentations, performances work-based supervisions, tests, quizzes, portfolios, tasks, individual and or collaborative tasks that usually attract a mark.

\section{Diagnostic/Pre- Assessment}

Its aim is to get to know the students' strengths, weaknesses, skills and knowledge they possess before taking the instruction.Can involve formal measurements, (e.g. IQ/aptitude tests, fitness) that are used to establish a starting point or baseline or informal measurements (e.g. observation, discussions, questioning). Diagnostic assessment informs programming, planning, learning and teaching methods used, as well as assessment choices (Murphy, 2009).

The assessment tasks that instructors provide to their students could be summative. This takes place after the learning has been completed and provides information and feedback that sums up the teaching and learning process. It also determines students' knowledge, skills and attitudes and contributes to their final grades. These gradesindicate whether the student has an acceptable level of knowledge gain to effectively progress to the next part of the class, course in the curriculum or level of academic standing. The assessment type is more products oriented and assesses the final product. Final examinations, term papers, thesis/dissertations, projects are examples of types of summative assessment (Murphy, 2009). These could also beformative/on- 
going/continuous.It provides information and feedback during the instructional process while learning is taking place and while learning is occurring (Murphy, 2009). The primary focus of formative assessment is to identify areas that may need improvement and also measures both the teacher and student's progress. These assessments are not graded but act as a gauge to students' learning progress and to determine teaching effectiveness, thus allowing the instructor to "rethink" and then "redeliver" content in such case when deficiencies are noted (Murphy, 2009). It usually takes place during day to day learning experiences and involves ongoing informal observations during in-class activities, feedback during lecture, in-class tests, assignments and group or individual oral presentation.

\section{Work-based learning Assessment}

The practice encourages employers to play an active part in student assessment as they carry out summative assessments for the student. However, the practice is associated with reliability difficulties as placements tend to be individualistic, some students tend to have better workplace opportunities to provide evidence of potential while others may be constrained into relatively routine work practices. As there is increased use of assessments made based on students in their work places care must be taken to ensure that consistency of equality in practice is offered in each workplace or placement. There is great need to involve the employers themselves in the assessment process so that they will not only feel part of the process, but also understand what is expected of them and the student. Do assess different placements differently in that some students will have a good experience while others may have an unsatisfactory experience. Consider using mentors if staff is available and willing in the workplace. In addition, portfolios are a valid way to assess work based learning (BoudRace, 1998). Boud Race(1998) further suggested the following types of assessments:

\section{Confirmative assessment:}

Its goal is to find out if the instruction is still a success after a year.

\section{Norm-referenced assessment}

This compares a student's performance against an average norm for example average national norm for the subject.

\section{Criterion}

It measures student's performance against a fixed set of predetermined criteria or learning standards. It checks what students are expected to know and be able to do at a specific stage of their education. Criterion-referenced tests are used to evaluate a specific body of knowledge or skill set, thus it's a test to evaluate the curriculum taught in a course.

\section{Ipsative assessment}

It measures the performance of a student against previous performances from that student.

\section{Assessment experiences of SwDs in Higher Education}

Assessment is one of the key components of the curriculum. It is a process of collecting and interpreting evidence in order to determine the student's progress in learning and to make a judgment about a learner's performance (Mbilini, 2012). Therefore, there is need for fairness to all students. However, most students with disabilities in HEIs have maintained that they face a number of challenges that hinder them from demonstrating their academic achievement and potential (Vickerman \& Blundell, 2010), yet higher education in particular is a predictor of gainful employment in meaningful occupations. The two authors in their study found that $11.1 \%$ of SwDs felt that their assessment did not meet their needs. With regards to the modification of assessment strategies that could be made in response to the needs of students with visual impairment (SVI), Gebrehiwot (2015) argues that SVIs could have been disadvantaged in some of the activities during the teaching and learning process and if assessment instruments are also biased towards activities that favour sighted students, such as by making considerable use of graphics, they would be doubly disadvantaged. The same author further suggests that the forms of assessment to be used in university classrooms should enable SVI to reveal the full range of learning they have achieved. In the situations where modifications are made in the learning outcomes, contents or learning activities, a corresponding variation has to be used in assessment process as well (Gebrehiwot, 2015).In Chiparaushe, Mapako and Makarau's (2011) study on challenges, opportunities and threats faced by students with disabilities at institutions of higher education in Harare, Bulawayo and Midlands provinces of Zimbabwe, students with disabilities who participated in the study expressed that they faced assessment challenges. Participants in this study indicated that only those students with visual impairment enjoyed extra examination time of up to $60 \%$, while, those who had other forms of impairments were left out. Similarly, students with visual impairment in Chataika's 2007 doctoral study explained that they were happy with 
examinations arrangements as they were allowed extra time and a separate examination room. One participant in that study had this to say:

"I am allowed a quarter of an hour extra time for reading and so on. It's adequate for most exams, ------------." Literature reveals that lack of inclusive assessment policy is a common practice in many countries in SubSahara. For example the two institutions in Gebrehiwot 2015's study did not have an assessment policy in place to guide instructors in making their assessment practices inclusive. There was no uniform and well organized practice of assessing students with visual impairment (SVI) in a fair way. In that research most of the accommodations provided were based on individual academic or administrative staff member's goodwill and discretion. That resulted in no accountability for failing to give any accommodations to SVI. Such scenarios have led to provision of lip and ad hoc services. In light of this, SVIs faced serious challenges related to individual assignments in particular and examinations. The following were some of the challenges encountered by SVIs in doing individual assignments: (a) lack of references in Braille (b) Lack of internet and internet skills (c) lack of support system to enable them to collect information outside the university campus (d) difficulty in writing assignments especially when extensive writing was required. In order to minimize the listed challenges instructors implemented the following strategies: (a) making SVI do the individual assignments in groups; (b) making them do one assignment where more than one assignment was given; (c) exempting SVI from doing individual assignments and make do with the test result; (d) assisting SVI choose manageable topics; (e) providing references for the questions SVI were assigned to do; (f) giving SVI assignment questions that were of less complexity than those given to other students (Gebrehiwot, 2015). In spite of all these measures being put in place to assist SVI, some students with visual impairment still expressed concerns with (a) examination format; (b) examination venue; (c) examination time; (d) support of assistants; (e) behavior of invigilators.

Wolanin and Steel (2004) have provided the following guidelines for adapting assessment for SVI:

- Provide assessment material like the exam or test of a lecture or tutorial in advance and in the student's preferred format, in print, Braille ;

- Encourage students with visual impairment to use 'paper/pen' substitutes such as tape recorders or laptops during exams for those with hand writing challenges;

- Allow students with visual impairment additional time, if required for assignments and examinations/assessments.

According to Sheffield Hallam University 2003, there are four strategies that can be considered in summative assessments for students with disabilities. These include (a) modifying assessments (b) others' support (c) time allowances (d) alternative assessments. Higher Education South Africa (2002) also proposed the following adjustments institutions may consider:

- Flexibility in the balance between assessed coursework and examinations

- Demonstration of achievement in alternative ways, such as through signed presentations or viva voce examinations

- Additional time allowances, rest breaks and re-scheduling of examinations

- The availability of examinations in alternative formats, for example in Braille, large print or audiotape.

- The provision of additional rooms and invigilators for those using alternative arrangements, if it is not possible to use the same examination room as other students.

Similarly Gebrehiwot (2015) gave the following as accommodations required by SVI to fully participate in the assessment process:

- Access to alternative or augmented forms of communication;

- Provision of tactile or kinesthetic materials;

- Time allowances; and

- Alternative assessments

In addition Salisbury (2008:40-41) describes the following strategies that could be considered in summative assessments for SVI

- Modifying assessments: This could enable SVI to have full access to the assessment without giving them any unfair advantage.

- Others' support:SVI may need the support of others in certain assessment activities, which they cannot do independently for instance, they may require readers and scribes in written examinations, they may also need others' assistance in practical activities such as using equipment, locating materials, drawing and measuring.

- Time allowances: SVI should be given additional time to complete their assessments to be decided by the individual instructor based on the purpose and nature of the assessment.

- Alternative methods of assessment: In certain situations where formal methods of assessment may not be appropriate for SVI, the instructor should assess those using non-formal methods such as class work, portfolios, or oral presentations. 
Another study conducted by Fuller et al. (2008) came up with the conclusion that most of the adjustments made in HEIs were "formulaic" and included provision of some facilities such as laptops-----, and giving extra time allowances during examinations.

These strategies play a very important role in facilitating access and participation of students with visual impairment in the assessment process. Technology has great potential in providing access for all learners and the ability to access the general curriculum. Assistive technology (AT) should not be viewed by educators within a 'rehabilitative' or 'remediative' context, but as a tool for accessing the curriculum and exploring out means to help students with disabilities achieve positive outcomes (Podzo \&Chipika 2019). Additionally, the two authors express that assistive technology has the potential to augment abilities and bypass or compensate for barriers that disabilities create. Consideration of AT is therefore required for SwDs so that they have the necessary tools to fully access and participate in the curriculum with the greatest possible level of independence. Tugli (2013) suggests the following new technologies and software options that HEIs can acquire for enhancing access to learning and assessment by SwDs:

- Text-to-speech devices

- Digital white board

- Speech synthesizers

- Print enlargers and document converters

- Scribe pen

- Visual/graphic outliners

- Visual tracking

- Phonetic spell checkers

- Voice input

Four participants in Waterfield and West's 2006 study express that they had been offered alternative assessments that met the module learning outcomes but importantly catered for the participants' strengths. One participant Amy had this to say:

The thought of standing in front of lots of people and delivering a presentation filled me with dread! I felt ill at the thought of it. It would not go away. I didn't want to let my lecturer to know about my illness but l finally spoke to her and she was great. I still did a presentation but in a room on myown with the lecturer, just the two of us.

However, the same study established that this willingness to offer other forms of assessment wasn't consistent throughout the university and was an issue raised by the nine participants. An example was given by Sarah who had difficulties with spelling and grammar and felt that alternative methods of assessment that acknowledged her strengths such as presentations or viva would have been beneficial to her, but was denied the opportunity for oral presentation. In the same vein Madriaga (2007) concedes that an over reliance on written assessments (including, exams) disadvantage some SwDs. Further to that some methods of assessments, including essays and exams can put students who are dyslexic at a disadvantage, as they may have difficulty in being able to express their thoughts in written form and suggest that alternative assessments such as presentations (including poster presentations) should be considered (Mullins and Preyde 2013). Taylor (2005) also reiterates the same sentiments on the importance of alternative assessments. The same author suggests that some groups of students may be "substantially disadvantaged" if alternative provision is not offered.In relation to that some SVI participants in Gebrehiwot's 2015 study had this to say:

When the examination includes questions that require writing you face problems. Your assistants may not write your answers accurately. There may be wrong spelling. Then the instructor may consider it wrong. If you try to tell him your intention he will tell you that he corrects the papers based on what is written and not on intentions. Of course they are right. Something has to be done to address our problem.

Undue privilege is given to the written work that when students with dyslexia for example have to be given an oral examination, lecturers and non-disabled students feel unfair advantage for the student with disability (Mullins and Preyde 2013:156). There seem not to be a universal solution to the problem due to the diversity of SwDs. Some SwDs and instructors are not Braille proficient hence use of Braille is not good for them, although use of computers may seem to be a solution, literature reveals that most SwDs lack enough computer skills and also lack of computers with the relevant software like JAWS (Podzo and Chipika 2019). Despite all these challenges cited by SVI in Gebrehiwot's 2015 study, there were certain accommodations for SVI. One of these was to substitute essay type test items with objective items. In some cases, SVI were exempted from the subjective questions without giving them questions in other formats as a substitute. Similarly, there were situations where SVI were exempted from test items that required sight or involved mathematical manipulations. One instructor in the same study had this to say:

The assessment l use although the content is similar sometimes the way it is presented might be different. I might ask the sighted students to observe visual material and write about it, at this time the scribe might fail to clearly 
describe the visual material to $S w D$ s in a way that they can have a mental image. Therefore, l prepare a question with a similar content but in a different way. The learning objective will be the same but the questions will be different for both groups of two students.

In the following studies (Fuller et al. 2004:41; Redpath, Kearney, Nicholl, Mulvenna, Wallace and Martin 2012:15-17), it was reported that many students with disabilities used to select courses based on the means of assessment to be utilized.

In this regard, Fuller et al (2004) write:

Students were eager to choose courses in which learning and assessment required little written work, or few or no exams and which had a substantial practical element or which was information technology based, for example voice recognition-software.

Waterfield and West (2008:91) underline that if SwDs were provided with choices of how they should be assessed it would have the effect that would greatly improve their learning experiences as well as their academic performance. In some instances, SwDs reported positive assessment-related experiences. In the study of Fuller et al., (2004:464), for example, one student with disability reported satisfaction about the variety of assessment mechanisms used in a certain course as follows:

The assessments of some of them (modules), they are really good and they vary. Like anatomy l did last semester and you have a skills test, an exam and a portfolio to hand in and it's good that they break it all up and l really enjoyed that module and everything that they said in the lectures related and it was really helpful.

Literature reveals that a number of SwDs prefer continuous assessment as the best way of assessment as they shun exams as they express that these are stressful and do not reflect true performance (Waterfield and West, 2008). Oneparticipant in the same study had this to say:

The assessment choices, $l$ have made all take away the onus from cramming unthinkable amounts of data/knowledge into just three hours(like an examination). I feel that coursework, ----- and peer evaluation would test my knowledge fairly and not my performance under stressful examination conditions.

This demonstrates further the uneasiness examinations create in SwDs. In addition another participant had this to say:

I find examinations extremely stressful particularly the period leading up to them. I experience panic attacks and become physically ill". Similarly another participant said "I tend to get stressed at examinations. Sometimes I am physically sick; examinations are and have always been a trial for me.

Ralph and Boxall (2005:372) suggest that SwDs are discriminated not only by actions committed in the institutions but also by omissions such as failure to provide information in formats appropriate for certain disabilities. Lecturers may fail to give expected support such as printed or soft copies of notes, giving alternative forms of assessments such as oral instead of written exam, allowing more time during tests and exams. Redpath, et.al. (2013) recommend that, wherever possible assessments should be designed from the start with the requirements of disabled people in mind. Participants in Lopez, Gavira and Morit (2015) acknowledged the support they received that included tutor support, extra time allowance of $25 \%$, a scribe, a reader, computer, specific coloured writing paper and individual room allocation.

Although Liasdou (2014) suggests that the practice of allocating SwDs a separate room to undertake an exam is a "segregating and stigmatizing form of provision", five of the participants in that study considered alternative room provision as a positive means of support. One participant had this to say:

I'm given a quiet room to do my exams in, obviously it is invigilated but sometimes l am literally on my own, it's brilliant! Sue.

Similarly another participant Helen had this to say:

$l$ have my exams in a separate room, it's much better and that means that $l$ can stand up and move around if $l$ need to without disturbing others.

In light of all this, it is therefore clear that an examination is one important curriculum element where students with disabilities need accommodations. Some of the participants had mixed experiences of assignment support from lecturers. Some participants expressed that they were given extension on the submission of their work although it was dependent upon individual lecturers. Couzens, Poed, Kataoka, Brandon, Hartley and Keen's (2015) study established similar findings. Participants expressed satisfaction over the support they received from the student support services although a few highlighted disappointments as their needs were not met. The participants expressed that there was a general "one size fits all" approach to a particular disability instead of being individualised. The research reveals that some participants would have preferred some assessments that catered for their strengths but a choice of assessment type was not an option for the majority and was dependent on individual lecturers with some being flexible and supportive whilst others were more rigid in their approach to assessment. Madriaga, Hanson, Kay and Walker's (2010) survey reveals that SwDs faced more difficulties on time limits set for assignments, physically writing and reading and some of the students' problems were attributed to poor teaching approaches by lecturers. SwDs in Norway who require accommodations were met with suspicion; students have to advocate for their needs despite institutions knowing about their 
impairments(Mosia2017).Students need support in all aspects of education including the academic, emotional and social demands of higher education. In light of that Mutanga (2015) recommends the establishment of a Disability Resource Unit and subsequent engagement of the Disability Officer/Technician. He/she acts as a broker of services, planner, manager, source of information and advocate for SwDs' services (Podzo and Chipika, 2019).

Kabuta's 2014 mixed methodology research on problems facing students with physical disabilities in higher learning institutions in Tanzania reveals that $75 \%$ of HEIs' infrastructures were available but inadequate, $85 \%$ was accessible with difficult to students with physical impairments whereby $35 \%$ and $25 \%$ of all infrastructure conditions were average and poor respectively. Further to that the study found high inadequacy of teaching and learning materials as well as lack of special schemes, trained staff, funds and scholarships for students with disabilities. $83.3 \%$ of the participants were of the opinion that examinations and other assessment procedures such as individual and group assignments, timed tests, projects as well as final university examinations measured what was intended while only $16.7 \%$ of the students explained that they were not measuring what was intended. The participants also expressed that they got enough time to prepare for their examinations and marking of test items were fair.

Madriaga, Hanson, Kay, Newitt and Walker's (2010) study reveals that students with disabilities faced more difficulties on time limits set for assignments, physically writing and reading. Some of the students' problems were attributed to poor teaching by lecturers. Ebersold's (2012) study is a comparative analysis of results of a survey conducted in 2006/07 in four countries, namely Denmark, Czech Republic, France and Norway. The results indicate that although $63 \%$ of the respondents said their access to tertiary education was very easy, support for their needs was not assured as universities and colleges mostly address physical accessibility and focus less on pedagogical, assessment, psychological and social accessibility. For these learners, besides having to cope with the trauma of a disability which might be mild, moderate, severe or profound, they also do face challenges in terms of gaining wider access to issues pertaining to the curriculum, teaching, learning, assessment and progression in the higher education institutions (HEIs), (Tugli 2013:56). As long as barriers exist in the curriculum more and more learners from disability categories will be excluded because of their specific disability needs that are not catered for.

Lecturers' ignorance and resultant attitude influence them to overlook students' challenges in class and make no adjustments to their teaching and assessment methods, thus leaving students vulnerable and lacking access to curriculum (Jelas and Mohd. Ali 2014:995). Positive perceptions from staff are associated with greater knowledge of the disability and lecturers' positive evaluations influenced them to be active and resourceful in seeking external support and adjusting their teaching and assessment to the needs of identified students (Cameron and Nunkoosing 2012). Wolanin and Steele (2004:41) in their report which they prepared for policy makers identified faculty attitudes and the culture as the major barrier to successful accommodations for SwDs in HE. On the part of instructors, problems such as mounting pressure and increasing workloads, as well as concerns on the lowering of academic standards when making adjustments were cited as other barriers to the implementation of accommodations for SwDs.

\section{Methodology}

The qualitative research approach was used in this study because it provides rich textual descriptions of people's feelings, values, experiences and perceptions of a phenomenon under investigation in their natural setting (Cohen, Mannion and Morrison 2007). Data collection involved individual interviews with students with disabilities, lecturers who teach these students and examinations department administration assistant at the chosen HEI. Selection was purposive and participation was voluntary. Data collected was thematically analysed. Students with disabilities were observed during their examination writing session.

\section{Findings and Discussion}

The findings are presented based on categorized themes that emerged from the researchers' initial readings and later modified through the process of reading and re-reading of the interview transcripts and observational notes. The findings are supported by extensive verbatim quotations from the responses of the research participants. The findings with regard to each theme are followed by brief discussions that include the researcher's own reflections. The categories that are used for presenting and discussing the findings are:

- SwDs experiences of:

- summative assessment

- formative assessment

- work-related learning (WRL)/ (Teaching Practice (TP) assessment

- Assistive Technology (AT)

- library services

- administrative support

- peer support

The assessment tasks that lecturers provide to their students were both summative (end of semester 
examinations-theory or practical in some cases) to determine students' knowledge, skills and attitudes and contribute to their final grades and formative (continuous/ongoing) designed to provide feedback and enrich students' learning. The continuous assessment was inform of individual assignments, group assignments/tasks, presentations, in-class tests and WRL/TP academic and institutional based assessment and WRL/TP action research assessment. Participants expressed mixed experiences which were both positive and negative.

\section{SwDs experiences of summative assessment}

All the students who participated explained that they were happy with examinations arrangements as they were allowed extra time and a separate examination room. Participants implored that they were allowed extra time of one and half hours which was enough for them. Blind students explained that their modes of writing examinations included oral (audio), use of the computer to Brailling which are modes they are comfortable with. However, those who use the audio mode complained that they at times experienced challenges with tape recorders and recommended that the Institution buy some new ones. These findings are similar to those of the following studies (Gebrehiwot 2015; Chiparaushe et al 2011). One participant in the study had this to say:

"I am allowed extra time for writing the examinations. It's adequate for most exams, ------------."

Students with visual impairment expressed challenges with examinations which involved calculations and recommended that special considerations be made in such cases. One student had this to say:

I was totally embarrassed when $l$ sat for a statistical paper and found out that l could not write anything and as a result l failed. How could they set questions which us as blind students cannot do, this shows lack of knowledge on inclusivity practices. They should have alternative questions for us.

In light of the above experience it is very important for institutions practicing inclusive education to consider alternative questions depending on the type of impairment a student might have so as to promote equal participation by all.

Most students expressed that they were satisfied with the assistance they got in practical examinations except one participant who had a different view.

\section{Assignment as a form of assessment}

Most of the participants expressed satisfaction on how coursework assessment was being implemented. Participants implored that the time they were given was enough, although they complained of lack of material in accessible formats. Visually impaired students explained that they relied heavily onreading material supplied to them by library staff as the Brailled material available could not be relevant. On the other hand most SVI relied more on peers as far as typing of assignments was concerned as all assignments were supposed to be computer typed even for those who use Braille as their form of writing. This was due to the fact that most lecturers were not Braille proficient. Lack of Braille competency among lecturers is a challenge which is experienced in many educational institutions globally as has been reflected in the following studies (Mahanya, 2016; Gebrehiwot, 2015). Therefore, there is need for staff training in this area.

\section{Teaching Practice Assessment Experiences}

The development of employable skills would no longer be confined to a university's premises and instructors. It would require the placement of students in different prospective employing organisations where they will be engaged in activities to develop their work-related experiences (Tennant et al, 2010). Educational institutions assesses the learning outcomes of the negotiated programmes with respect to a framework of standards and levels. Students who participated in this study expressed mixed experiences of the work-related (Teaching Practice) exercise. Most of the participants expressed that they benefited much as they had hands on experience. However, participants explained that they faced challenges of engaging competent assistants as they did not receive any allowances like other students in tertiary institutions. As such, they had to find a relative who was willing to assist them for the whole period. This really affected the quality of work especially on documentation. Basing on this participants recommended that the Ministry of Higher and Tertiary Education, Science and Technology Development considers paying allowances to students with disabilities in HEIs when they are on TP since they have additional costs associated with some demands related to their conditions. One participant had this to say:

It is embarrassing that your actual performance may not be realized just because you could not secure a competent assistant. Really something must be done in this respect so that we are able to access and participate in educational activities just like other students without impairments.

Some participants pointed out lack of resources like stationery as other barriers to their successful participation.

\section{SwDs Experiences with Library Services}

One important resource centre in HEIs where students are expected to access to a wide range of academic information and enrich their learning experiences is the library (Gebrehiwot, 2015). Most studies done on this subject reveal that libraries posed difficulties of access to information like Braille and electronic formats, 
inaccessible for students with physical impairments, no reading room for students with visual impairment and no computers with JAWS software. In some cases students with physical impairments find difficulties in moving around the library due to poor furniture arrangement. Findings of this study reveal that students could not access reading material in accessible format like Braille. Further to that students could not get relevant assistance in using computers to search for information as most of the library staff are not conversant with the use of computers installed with JAWS software. As a result, most students relied on information some library assistants could search for them. One participant had this to say:

I can't search information on my own and l have to rely on others for information and this has grossly affected me as $l$ cannot do my assignments in time. At times $l$ have to wait as all people mighty be busy. Surely the university has to do something to alleviate this situation. We must be accorded the same treatment just like other students without impairments.

Another student had this to say:

I need reading material in large print as $l$ have challenges with small print, but there is nothing like that. The situation has forced me to strain my sight and truly speaking its affecting my eyesight and academic life negatively. I wish the institution could consider my situation.

\section{Experiences with AT}

The challenges SwDs face in the learning environment due to their impairments can be minimized with the help of assistive technology. This refers to the software tools and hardware equipment that assist SwDs in their learning. It is essential that, as far as capacity and resources allow, institutions should provide necessary assistive technologies to SwDs just as they provide learning resources for other students. SwDs should be provided with training on how to make use of those technologies. SwDs in the present study recognised the role assistive technologies could play, especially in widening opportunities in their studies.Similar observations were made by participants in Gebrehiwot's 2015 study. The digital voice tape recorder was one of the ATs blind students found useful in their day to day academic experiences. However, there was general feeling that most of the tape recorders' life span had expired as most students experienced challenges during their daily use and even during examinations. One participant had this to say:

------the university has given us recorders. However, most of the tape recorders have challenges so much that one blind student nearly lost all the examination material recorded during one examination session.

The traditional technology most students with visual impairment use for learning purposes is Braille (Gebrehiwot, 2015). Students with visual impairment in this study encountered two major problems. One problem was that there was little material in Braille that was relevant to their studies. Secondly, they could not convert the soft copies of handouts they were given into Braille because: there is no Disability Resource Unit which can provide Brailling services; the only embosser available broke down. The other challenge was that two visually impaired students acquired the visual impairment later in life and they were not Braille proficient. To make the situation worse the University did not make effort to train such students in using Braille.

One technology which is of immense value for learning purposes, to both disabled and non-disabled students, is the computer (Gebrehiwot, 2015:171). However, most of the participants expressed some challenges in its use since they lacked skills and further to that very few computers are installed with the JAWS software, instead they use their phones.

\section{Administrative Support}

The effectiveness of the support and accommodations SwDs are provided, to a large extent, depends on the awareness, skills and attitudes of those responsible for providing it (Gebrehiwot, 2015). One of the barriers SwDs faced in their educational journey was related to their administrators' awareness and attitudes. Most participants expressed that some administrators were not aware of the educational, social, systems and access challenges they were facing. Although the participants expressed that the support they were receiving from the administration as being fair they felt more can be done. Participants expressed that they received support such as provision of some AT, extra time during examinations writing and representation in the Students Council but felt more can be done as can be seen in the following interview excerpt:

We appreciate what the administration is doing for us, however more needs to be done like awareness campaigns, repairing and replacement of some AT, modification and adaptation of the environment and provision of such services like Brailling of our reading materials, orientation and mobility training as well as the establishment of a Disability Resource Unit.

Similar findings were made in researches by (Tirusew, Daniel, Alemayehu, Fantanahuni, Sewalem,Tilahin, Yirgashewa and Yeshitila 2014; Vickerman and Blundell 2010).

Further to that participants especially those with visual impairment complained of constant change of lecture rooms. This practice negatively affected them as they wasted time looking for the lecture rooms resulting in loss of learning time. One participant had this to say: 
It is so disappointing that lecture rooms are changed without notice and one has to waste time looking for the alternative venue. This has caused mobility challenges especially for us with visual impairment. Really something must be done so that we have permanent lecturerooms.

According to Gebrehiwot (2015), the most important prerequisite for the establishment of an effective support system is the development of policies and guidelines that serve as a legal framework for all their operations. Many universities of the western world have developed institutional policies (The Quality Assurance Agency for Higher Education, 2010). Bell (2013) argues that lack of coherent policy and legal frameworks regarding students with disabilities' rights and entitlements in the HEIs of Sub-Saharan Africa was identified as a major problem. The findings of this study, likewise indicate that the HEI in this study did not have legal policy or if the policy is there it was not made known to students. This is revealed by the following excerpt by one of the participant:

I don't know of any disability policy and if it is there it was not publicized. I encourage the University to have one and make it public.

Basing on this finding it suggests that existing support was based on spontaneous decisions and goodwill of individual academic or administrative staff.

\section{Peer Support}

Participants had mixed experiences over this issue. Some participants expressed satisfaction and appreciation over peer support whilst others had negative experiences. Participants explained that they got support in areas like orientation and mobility, reading of printed material, typing of assignments as well as social support. One participant had this to say:

I am happy with the support $l$ get from my peers, they are quite cooperative and accommodative although $l$ sometimes incentivize them by some little tokens.

On the other hand some participants expressed that some peers were not ready to offer services for free as they asked for some favours in exchange for services they would have offered. One SVI had this to say with regards to that:

I sometimes face challenges when 1 need assistance from sighted peers. They would openly say 'nothing is for mahala' meaning that there is no free service. At times they would ask me to do Braille exercises for them in exchange for services $l$ may want from because they are not proficient in that and if l could not do that due to my own academic commitment they would not assist me in return. So really life is sometimes very difficult for me.

In view of these experiences participants suggested that if the Institution could incentivize those willing to assist SwDs by may be offering them free accommodation on campus and also hold regular awareness campaign sessions with students and staff members.

\section{Conclusion}

The study concludes that SwDs still experience assessment challenges although to some extent HEIs have some measures in place to their benefit. As such, HEls, the government through the relevant Ministry and all stakeholders are encouraged to collaborate so as to improve access and participation of students with disabilities in HE.

\section{Recommendations}

1. HEIs should ensure provision of reasonable accommodations which are intended to facilitate equality of participation in education through Universal Design Learning which refers to the design of curricula, teaching practices, assessment methods, support services and physical environments that can accommodate the ever-increasing diversity of students in higher education.

2. In order to ensure that appropriate support is in place, it is important that HEIs continue to encourage SwDs to disclose their disability status prior to commencement of studies, thus HEIs are encouraged to be more proactive in encouraging students to disclose through awareness campaigns.

3. HEIs are encouraged to hold regular and compulsory training of staff on disability issues.

4. The study also recommends a collaborative approach by major stakeholders like staff and SwDs towards development of future policy that ensures inclusive practices across all departments. Such policies should consider differing modes of academic delivery and forms of assessment.

5. Institutions should invest in the provisions of assistive technologies to SwDs just as they provide learning resources for other students.

6. Students with disabilities should also be provided with training on how to make use of those technologies.

7. Libraries and other study centres should be equipped with computers with appropriate software and that support staff in such centres should be trained in the ways of providing necessary support for SwDs. 


\section{References}

Ashworth, M., Bloxham, S. and Pearce, L. 2010. Examining the tension between academic standards and inclusion for disabled students: The impact on marking of individual academics' frameworks for assessment. Studies in Higher Education, 35 (2). pp. 209-223.

Bell, D. 2013. Investigating teaching and learning support for students with learning impairment at a university in the Western Cape. Doctoral Thesis. University of Stellenbosch: South Africa.

Boud Race, P. (1998). The Lecturer's Toolkit $2^{\text {nd }}$ Edition: Kogan Page Ltd.

Brunton, K. \& Gibson, J. 2009. Staying the course: the experiences of disabled students of English and Creative Writing. Forum.http://www. Tnyurl.com/klgclb (accessed o9 January 2019).

Cameron, H. and Nunkoosing, K. 2012. Lecturer perspectives on dyslexia and dyslexic students within one faculty at one university in England. Teaching in Higher Education, 17(3):341-352.

Cameron, L. 2001. Teaching Languages to Young Learners. Cambridge: Cambridge University Press.

Chataika, T. 2007. Inclusion of disabled students in higher education, In Zimbabwe: from idealism to Reality Social Ecosystem Perspective.

Chiparaushe, B.,Mapako, O. and Makarau, A. 2011. A Survey of Challenges, Opportunities and Threats Faced by Students with Disabilities in the Post -Independent Era in Zimbabwe. Harare. Students Solidarity Trust.

Cohen, L., Manion, L. and Morrison, K. 2007. Research methods in education ( $\left.6^{\text {th }} \mathrm{Ed}\right)$. London Routledge Taylor and Francis Group.

Couzens, D., Poed, S., Kataoka, M., Brandon, A., Hartley, J. and Keen, D. (2015). Support for students with disabilities-

Ebersold, S. 2012. Transition to tertiary education and work for youths with disabilities, education and training policy OECD publishing. Available at http;//dxdoi.org/10.1787/9789264177895-en [Accessed 15 March 2019].

Elton, L. (2004) 'A challenge to established assessment practice' Higher Education Quarterly 58,1,43-62.

Fuller, M., Georgeson, J., Healey, M., Hurst, A., Riddell, S., Roberts, H. and Weedon, E. (2008) Disabled students in higher education experience and outcomes. [online] Briefing 46. Available from: http://www.Ilrp.org/pub/documents/Fuller\%20RB\%2046\%20FINAL.pdf[03March 2019].

Fuller, M., Healey, M., Bradley, A., and Hall, T. 2004. Barriers to learning: a systemic study of the experience of disabled students at one university. Studies in higher education 29(3), 303-318

Gavira, R. and Morina, A. 2015. Hidden voices in Higher Education. Inclusive policies and practices in Social Science and Law Classrooms. International Journal of Inclusive Education, 19, 365-378.

Gebrehiwot, Y.G 2015. Towards more inclusive University Curricula: the learning experiences of visually impaired students in HE institutions in Ethiopia. A D E D This is UNISA.

Haihambo, C.K.2010. Inclusive Education: Challenges of SWDS in Institutions of Higher Education in Namibia, DED Thesis, University of South Africa.

Howell, C. 2006. "Disabled students and Higher Education in South Africa." Human Sciences Research Council Press: Cape Town. 164-178.

Ioannou-Georgiou, S. 2003. Assessing Young Learners (Resource Books for Teachers). Oxford.

Jelas, Z.M. and Mohd.Ali, M. 2014. Inclusive education in Malaysia: Policy and Practice. International Journal of Inclusive education, 18 (10): 991-1003.

Kabuta, L. G. 2014. Problems facing Students with Physical Disabilities in Higher Learning Institutions in Tanzania. Open University of Tanzania.

Kolar, Z. and Renata, S. (2005). Hodnocen: Zaku Praha: Grada Publishing.

Kratochvilova, J. (2011). System hodnoceniasebebodnocenizaku: Zkusenosti z Ceske republiky: iEvropskychskol. Brno: MSD spol.sro.

Leathwood, c. (2005). Assessment policy and practice in higher education: purpose, standards and equity, Assessment and Evaluation in HE 30,3, 507-324.

Lerner, J.W. \& John, B. 2012. Learning disabilities and related mild disabilities. Characteristics, teaching strategies and new directions. $12^{\text {th }}$ ed. Wadsworth: Cencage Learning.

Liasidou, A. (2014) Critical disability studies and socially just change in higher education, British Journal of Special Education, 41, 120-135.

Liasidou, A. 2012. Inclusive Education and critical Pedagogy at the intersections of disability, race, gender and class. Journal for critical Education Policy Studies, Volume 10, Issue No 1, Pp. 168- 184.

Madriaga, M., Hanson, K., Kay, H., Newitt, S. and Walker, A. 2010. Confronting similar challenges? Disabled and non-disabled students' learning and assessment experiences. Studies in Higher Education, 35 (6), $647-$ 658.

Madriaga, M. 2007. Enduring disablism: students with dyslexia and their pathways in UK higher education and beyond. Disability and Society, 22,4, 399-412.

Makanya, S. 2015. Investigating FET College Lecturers' Experiences of the Inclusion of Students with 
Disabilities in a Mainstream Classroom. A Master's Thesis. University of KwaZulu-Natal, Edgewood Campus, Pinetown, South Africa.

Mbilini-Kuze, B. W. C. 2012. The Implementation of Tourism Curriculum in Secondary Schools in Fort Beaufort Education District Eastern Cape Province: Implications for Sustainable Tourism. A PhD Thesis, Fort Hare University. South Africa.

Mokiwa, S, A. and Phasha, T. N. 2012. Using ICT in an Open and distance learning (ODL) institution in South Africa: The learning experiences of students with visual impairments, Africa Education Review, 9 (1), 136151.

Morley, L. (2003). Quality and Power in Higher Education Maidenhead:SRHE and Open University Press.

Mosia, P. A. 2017. Access to Higher Education for Students with Disabilities in Lesotho. A DED Thesis. UNISA.

Mullins, L. and Preyde, M. 2013. The lived experiences of students with an invisible disability at a Canadian university. Disability and Society, 28 (2): 147-160.

Murphy, F. 2009. Assessment Types: Module Design and Enhancement.

Mutanga, O. 2015. Experiences of Disabled Students at two South African Universities: A Capabilities Approach. A PhD Thesis. University of the Free State, Bloemfontein, South Africa.

Nkoane, M. M. 2006. An Analysis of factors inhibiting the access of students with special needs to Higher Education in the Free State. The Centre for Higher Education Studies and Development. Faculty of the Humanities. Bloemfontein: University of the Free State.

Podzo, B. Z. and Chipika, C.G. 2019. Curriculum Reform: A Key Driver to the Inclusion of Students with Disabilities in Higher Education. Journal of Education and Practice. www.iiste.org ISSN 2222-1735 ISSN 2222-288X DOI: 10.7176/JEP Vol. 10, No. 6.

Ralph, S. and Boxall, K. 2005. Visible images of disabled students: An analysis of UK university publicity materials. Teaching in Higher Education, 10(3): 371-385.

Redpath, J., Kearney, P., Nicholl, P., Mulvenna, M., Wallace, J. \& Martin,S. 2013. A qualitative study of the lived experiences of disabled post-transition students in higher education institutions in Northern Ireland, Studies in Higher Education, Vol. 38, No. 9, 1334-1350

Rose, D. and Meyer, A. 2000. 'Universal Design for Learning' Journal of Special Education Technology, Volume 15 No. 1.

Salisbury, R. (ed). 2008. Teaching Pupils with Visual Impairment: Aguide to making the school curriculum accessible, London. Routledge

Shakespeare, T, 2006. Disability right and wrongs. London: Routledge.

Sharp, K. and Earle, S. (2000). Assessment, Disability and the problem of Compensation Assessment and Evaluation I HE 25,2, 191-199.

Shepherd, I. D. H. 2006. Developing an Inclusive Curriculum for Visually Disabled Students, University of Gloucestershire.

Stuart, M. 2002. Collaborating for change? Managing widening participation in Further and Higher Education NIACE: Leicester

Taylor, M. J. (2005). Teaching students with autistic spectrum disorders in Higher Education. Education and Training 47. 484-495.

Tennant, M., McMullen, C. and Kaczynski, D. 2010. Teaching, Learning and Research in Higher Education: A Critical Approach, New York: Routledge.

Tinklin, T., Riddell, S. and Wilson, A. 2004. 'Policy and Provision for Disabled students in higher education in Scotland and England: the current state of play', Studies in Higher Education, Vol, 29. No. 5, 637-657.

Tirusew, T., Daniel, D., Alemayehu, C., Fantanahun, A., Sewalem, T., Tilahun, A., Yirgashewa, B. and Yeshitila, M. 2014. Assessment of the students with disabilities in the Ethiopian universities, unpublished research report, Addis Ababa University.

Tugli, A. K. 2013. Challenges and needs of learners with disabilities in an inclusive institution of higher education in the Limpopo Province of South Africa. Unpublished PhD Thesis, University of South Africa.

Vickerman, P. \& Blundell, M. 2010. Hearing the voices of disabled Students in Higher education, Disability and Society Volume. 25, No 1, Pp 21 - 32.

Waterfield, J. and West, B. 2006. Inclusive Assessment in Higher Education: A Resource for Change. University of Plymouth: Plymouth.

Wolanin. T.R. \& Steele, P.E. 2004 Higher Education Opportunities for Students with Disabilities: A Primer for Policy Makers, The Institute for Higher Education Policy. 